\title{
Penerapan TQM dalamlembagapendidikan
}

\author{
Oleh \\ Muhaimin S \\ Mahasiswa aktif semester 4 manajemen pendidikan islam \\ fakultas agama islam universitas nurul jadid
}

Abstrak

PenerapanTqmdalamdalamlembagapendidikanadalahsuatucarauntukmenjadikansuatulem bagapendidikan agar bisabersaingdanmemilikikualitaspendidikan yang baik, tqm di sinisebagaipatokaan agar

suatulembagapendidikantetapmaksimaldalammenjalansistemnyadengandemikianketikatqmmaksi malmakatidakmenutupkemugkinanbahwalembagapendidikanituakanbanyakpeminatnyakarenama syarakatakanbanyak yang memasukananaknyauntukmenempuhataumencariilmu di lembagatersebutkarenalembagatersebutdinilaiberhasilmenjalankantugasnyadenganbaikdanmamp umencetakoutputnyadengankualitas yang berkualitas

\section{PENDAHULUAN}

Dalam suatu lembaga kita di tuntut untuk bisa memajukan atau menerapkan sistem yang bagus agar para peserta didik yang akan masuk atupun yang sudah ad di sana bisa mendapatkan suatu pembelajaran yang baik, dengan perkembangan zaman dan jga ancamana globalisasi yang semakin cangggih ini kita di tuntut untuk bersaing dengan organisasi atu lembaga pendidikan lain

Berangat dari situ kita harus tau dan mengerti tentang cara atau mengimplementasikan suatu sistem yang baik, kemudian kalau sudah menghasilkan hal yang baik makan kita atu lembaga kita akan banyak peminatnya dan pandangan masyarat tentang lembaga kita akan baik.

\section{A. ImplementasiTQM dalamPendidikan}

Ketikadikaitkandengankonteksaplikasinyadalamkonseppendidikan, maka Total
Quality $\quad$ Manajementdapatmenekankanpadaduakonseputama.Pertama,
$\begin{aligned} & \text { sebagaisuatufilosofiperbaikanterusmenerus } \\ & \text { dankeduaberhubungandenganalat-alatdantekhnikseperti }\end{aligned}$


dananalisiskekuatanlapangan, digunakanuntukperbaikankualitasdalamtindakanmanajeenuntukmencapaikebutuhadanhar apanpelanggan.

Akan tetapi Total Quality Management dalampendidikantelah di ucapkanolehSallis, bahwa Total Quality Management berhubungandenganpenciptaanbudayakualitasdenganmemposisikantujuankaryawandanst afuntukmenyenangkankonsumensekaligusdidukungolehorganisasimerekadanmelakukans esuatu yang dikehendaki.

Untuk bisa menyenangkan konsumen dalam pendidikan maka perlu perbaikan program sekolah yang mungkin dilakukan secara lebih kreatif dan konstruktif, dan yang paling vital adalah bagaimana mutu kualitas dalam programnya dapat mengobah kultur sekolah para pelajar dan orang tuanya menjadi tertarik dengan adanya inovasi yang ditimbulkan oleh TQM.

Franklin

P.

Schargelmenegaskanbahwamututerpadupendidikandipahamisebagaisuatu proses yang melibatkanpemusatanpadapencapaiankepuasanharapanpelangganpendidikan,

perbaikanterus-menerus, pembagiantanggungjawabdenganparapegawai, danpenguranganpekerjaantersisadanpengerjaankembali.

Dalamrangkamelaksanakanpeningkatankualitaspendidikanperlumelaksanakanmet ode yang dikenaldenganmetode PDCA (Plan-Do-Chek-Act).Metodeinipertama kali dikembangkanolehShewarddandivisualisasikanolehDeming

,berupasiklusPDCABerangkatdarisiklus

di atasbisadiambilpengertiandenganbeberapatahapan, yaitu: ${ }^{1}$

1. Plan yang mana plan disiniberisikantentangperbaikan proses

2. Do, pengumpulan data apakahadahal yang akan di perbaiki

3. Check, yaitulangkahpemimpinuntukmenganalisishasilimplementasi (suksesatautidaknya) atauproses seorangpemimpinuntukmemperolehilmu yang barutentangsuatujabatan yang di sandarkanatau di emban

4. Act,yaitupengambilahhasilsuatukeputusan yang hendak di terapkan, penyusunancarabaku, pelatihanulangbagibawahan yang membutuhkanpelatihan,

\section{B. Hambatan TQM dalamlembagapendidikan}

Suatu

proses tanpaadasuatugodaaannyamakamungkikekekebalanorganisasiitutidaktahanlama ataumudahruntuh, mengapademikian? Karenasemakinbanyakgodaanatauujian yang organisasiituterimadanbangkitlagiitusudahmununjukkanbahwa orang yang

\footnotetext{
${ }^{1}$ Hardjosoedarmo, Soewarso. Total Quality Management. Yogyakarta: 2002
} 
adadalamnyaadalah orang-orang yang hebatberikutiniadalahkendala-kendala yang sering di alamiolehsuatulembagapendidikan $2^{2}$
1. Adanyapenyelewengan di antarabelahpihak misalkanseorangpemipinmembutuhkanhasilsuatu data tapianggotatidakmengasi data tersebut
2. staftidakmemahamitujuandanmisilembaga;
3. adanyakonflikeksternal yang di bawa-bawasampaikelembagapendidikan
4. kurangpengawasandariseorangkepalakepadaanggotanya

\section{Fase-FaseImplementasi TQM}

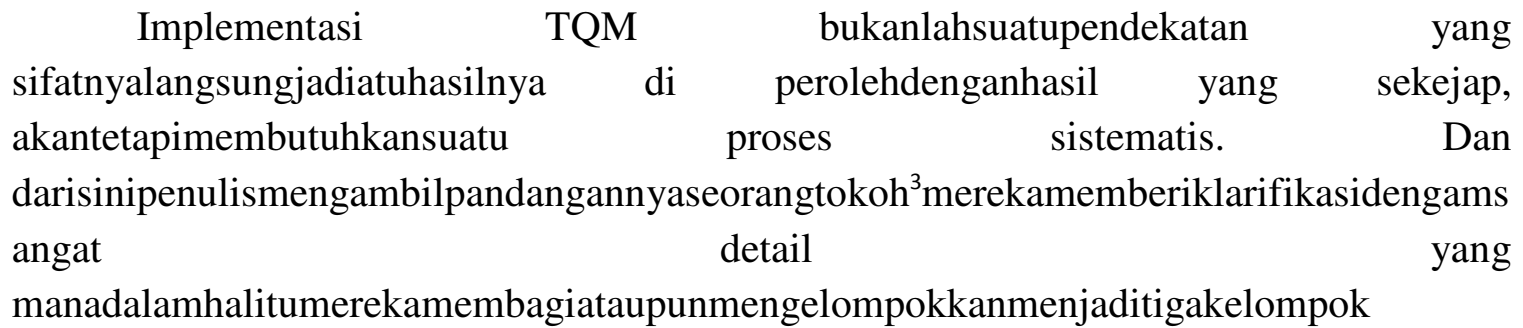

1. fase persiapan

di fase ini terdapat sepuluh langkah, dan syarat yang harus ada sebelum melakukan langkah yang pertama adalah adanya komitmen penuh dari manajemen puncak atas waktu sumberdaya yang di butuhkan
a. langakahpertamaadalahMembentuk Total Quality Streering Committee
b. Membentuk Tim
c. Pelatihan TQM
d. Menyusunvisidanprinsipsebagaipedoman
e. Menyusuntujuanumum
f. Komunikasidanpublikasi
g. Identifikasikekuatandankelemahan
h. Indentifikasipendungdanpenolakan
i. Memperkirakansikapkaryawan
j. Mengukurkepuasanpelanggan

2. Faseperencanaan

a. Identivikasiproyekataumasah

\footnotetext{
${ }^{2}$ Creech, Bill. Lima Pilar TQM.Dialihbahasakanoleh Alexander Sindoro.Jakarta: Binarupa, 1996.

${ }^{3}$ Arifin, A.A (1990), " Berangkat dari konsep Crosby", manajemen, No, 78, 46-49
} 
b. Komposisitim

c. Pelatihantim

3. Fasepelaksanaan

a. Penggiatantim

b. Umpanbalik

c. Umpanbalikdaripelanggan

d. Umpanbalikdarikaryawan

e. Memodifikasiinfrastruktur

\section{Kebutuhan peribahan yang harus di hindari}

Dalam implementasi TQM, tidak ada satupun rumus kiat atupun cara tertentu yang berlalaku universal dan dapat menghasilkan kesuksesan dalam segala kondisi dan untuk semua organisasi. Setiap organisasi harus mengadaptasi ide-ide dan tehnik-tehnik yang sesuai dengan situasi organisasinya, kekuatan dan kelemahan yang di miliki, budaya organisasi, dan situasi bisnis yang di geluti organisasi tersebut Berikut ini adalah beberapa hal yang harus di hindari. ${ }^{4}$

1. Jangan melatih semua karyawan sekaligus

2. Jangan tergesa-gesa menerapkan TQM dengan melibatkan terlalu banyak orang dalm suatu tim

3. Implementasi TQM tidak boleh di delegasikan

4. Jangan memulai implementasi bila manajemen belum benar-benar siap

\section{E. Kebutuhan akan perubahan}

\section{Kekuatan eksternal}

- Karakteristik pemografi

- Usia

- Pendidikan

- Tingkat keterampilan

- Jenis kelamin

- Imigrasi

\section{a. Kemajuan technologi}

- Otomatisasi pemanufakturan

${ }^{4}$ Kreitner, R. Dan A. Kinicki (1992), Organisasi. Yogyakarta:2014 
- Otomatisasi kantor

b. Perubahan Pasar

- Merjer dan akuisisi

- Persaingan domestik dan internasional

- Resesi

c. Tekanan sosial dan politik

- Perang

- Nilai-nilai

- Kepemimpinan

\section{Kekuatan internal}

a. Permasalahan / Prospek SDM

- Kebutuhan yang tidak terpenuhi

- Ketidak puasan kerja

- Absensi dan turnover

- Produktivitas

- Partisipasi / saran

b. Perilaku / Keputusan Manejerial

- Konflik

- Kepemimpinan

- Sistem penghargaan (reward)

- Reorganisasi struktual 


\section{DAFTAR PUSTAKA}

Creech, Bill. Lima Pilar TQM.Dialihbahasakanoleh Alexander Sindoro.Jakarta: Binarupa, 1996.

Hardjosoedarmo, Soewarso. Total Quality Management. Yogyakarta: Andi Yogyakarta, 2002.

Dikutipdari: Ibrahim, Amin. Pokok-

PokokAdministrasiPublikdanImplementasinya.Bandung: RefikaAditama, 2008.

Zamroni\&BaharunHasan.ManajemenMutuPendidikan, IkhtiardalamMeningkatkanMutuPendidikan Madrasah melaluiPendekatan Balanced Scorecard.Tulungagung: AkademiaPustaka, 2017.

Soedarmo, Harjo, 1997, Dasar-Dasar Total Quality Management, Yogyakarta, Andi2003, 